\title{
Authors' reply to Brusasco and colleagues and Quanjer and colleagues
}

\author{
Francesca Conway academic foundation year 2 doctor, Azeem Majeed general practitioner and \\ professor of primary care, Graham Easton general practitioner and lead for education research
}

Department of Primary Care and Public Health, Imperial College London, London W6 8RP, UK

In their responses to our article, ${ }^{1}$ Brusasco and colleagues and Quanjer and colleagues suggest that current NICE guidelines on the management of chronic obstructive pulmonary disease (COPD) may lead to overdiagnosis in older people and underdiagnosis in younger people because of age related changes in lung function. ${ }^{2}$

Although this is possible, the use of a measure of lung function such as the lower limit of normal rather than the $\mathrm{FEV}_{1} / \mathrm{FVC}$ (forced expiratory volume in one second/forced vital capacity) ratio $<0.7$ could lead to underdiagnosis in some groups. ${ }^{4}$ All measures of lung function have limitations in terms of accuracy, ease of use in clinical practice, and cost effectiveness when used to diagnose COPD. NICE is due to review its COPD guidance in 2016 and will systematically evaluate data from studies that have assessed the accuracy of measures of lung function in the diagnosis of COPD. Without seeing the results of such a systematic review, it is not possible to state categorically that a fixed $\mathrm{FEV}_{1} / \mathrm{FVC}$ ratio; a ratio adjusted for age, sex and height; or some other measure of lung function should be used to diagnose COPD.

Although there was not space in the article to go into the details of this important debate, we are grateful that these authors mentioned this problem. Whatever diagnostic criteria are used to diagnose COPD, it is important that patients with COPD receive an accurate diagnosis so that they can benefit from treatment and for the current gap between predicted and diagnosed prevalence to be narrowed..$^{5}$

Competing interests: None declared.

1 Brusasco V, Pellegrino R, Miller MR. Arbitrary thresholds of natural variability and severity Bhould not be used to diagnose chronic obstructive pulmonary disease. BMJ 2016.352.j393. Quanjer $\mathrm{PH}$, Steenbruggen I, van den Berg JW. Diagnosis of airways obstruction should be based on symptoms and an $\mathrm{FEV}_{1} / \mathrm{FVC}$ ratio below the lower limit of normal. $B M J$ 2016;352:1397

3 Conway F, Majeed A, Easton G. Diagnosing chronic obstructive pulmonary disease. BMJ 2015;351:h6171. (24 November.)

4 Güder G, Brenner S, Angermann CE et al. GOLD or lower limit of normal definition? A comparison with expert-based diagnosis of chronic obstructive pulmonary disease in a prospective cohort-study. Respir Res 2012;13:13.

5 Nacul L, Soljak M, Samarasundera E. COPD in England: a comparison of expected, model-based prevalence and observed prevalence from general practice data. $J$ Public Health 2011:33:108-16.

Cite this as: BMJ 2016;352:1400

๑ BMJ Publishing Group Ltd 2016 